\title{
Does Subjective Well-Being Affect Political Participation?
}

\author{
Annika Lindholm*
}

Abstract: Subjective well-being (SWB) has been positively correlated with political activity, however the causality of the effect remains debated. By estimating within-individual effects, I show that SWB decreases protest intentions, while its effect on voting is not significant. Despite the mutual influence between SWB and protest, the results suggest that the influence of SWB on protesting is stronger than the reverse effect, thereby setting an agenda for future research in this domain.

Keywords: political participation, political protest, subjective well-being, fixed effects, causality

\section{Le bien-être subjectif affecte-t-il la participation politique?}

Résumé: Le bien-être subjectif (SWB) a été corrélé positivement avec l'activité politique, mais la causalité de l'effet reste discutée. En estimant des effets intra-individuels, je montre que SWB diminue les intentions contestataires, alors que son effet sur le vote n'est pas significatif. En dépit de l'influence réciproque entre SWB et la contestation, les résultats suggèrent que l'influence de SWB sur la contestation est plus forte que l'effet inverse, établissant ainsi un agenda de recherche future dans ce domaine.

Mots-clés: participation politique, contestation politique, bien-être subjectif, effets fixes, causalité

\section{Beeinflusst subjektives Wohlbefinden die politische Partizipation?}

Zusammenfassung: Das subjektive Wohlbefinden (SWB) korrelierte bislang positiv mit politischer Aktivität, die Kausalität des Effekts bleibt jedoch umstritten. Mittels Schätzung intra-individueller Effekte zeige ich, dass das SWB die Absicht, an Protesten teilzunehmen verringert, während es sich nicht signifikant auf die Abstimmungsteilnahme auswirkt. Trotz der gegenseitigen Beeinflussung von SWB und Protest deuten die Ergebnisse darauf hin, dass der Einfluss des SWB auf das Protestieren stärker ist als der umgekehrte Effekt, und legen somit eine Agenda für zukünftige Forschung in diesem Bereich fest.

Schlüsselwörter: politische Partizipation, politischer Protest, subjektives Wohlbefinden, fixe Effekte, Kausalität 


\section{Explaining participation from a well-being framework}

\subsection{Introduction}

This research sheds light on the mechanism that connects subjective well-being (SWB) and political engagement. Previously, research on participation strongly focused on the role of personal resources, notably time, money, or civic skills (Barnes et al. 1979; Brady et al. 1995; Stolle and Hooghe 2011), or on mobilising contextual factors (Verba et al. 1987; Rosenstone et al. 1993; Dalton 2006), in explaining interindividual differences in political activity. Meanwhile, it is increasingly recognised that political engagement does not only stem from the available opportunities or the (objective) resources that individuals have at their disposal, but it is also likely affected by individual psychological factors, which may become additional resources, or obstacles, for participation (Taylor et al. 2000; Hobfoll 2002). There is a pressing need to further investigate into the psychological explanations to why some people choose to take part in political activities, while others opt out.

SWB is considered a psychological state that influences both public and private life (Veenhoven 2008), in addition to having intrinsic and instrumental value of its own (Samman 2007). SWB has been found to be positively correlated with political participation in several studies (e.g. Klar and Kasser 2009; Flavin and Keane 2011; Weitz-Shapiro and Winters 2011; Bühlmann 2016), yet much of the existing research uses cross-sectional methods to test a relationship that has often been assumed to run from participation to higher well-being (Frey and Stutzer, 2000; Radcliff 2001; Klar and Kasser 2009; Pacheco and Lange 2010; Bühlmann 2016). Only a few studies have systematically tested whether political participation favours the development of SWB, or if SWB instead nurtures participation (exceptions include Weitz-Shapiro and Winters 2008, 2011; Pirralha 2017).

\subsection{Aim}

This research contributes to filling the gaps in the literature by examining individual trajectories of well-being and political engagement in Switzerland, thereby clarifying the causal mechanism between the two. The Swiss case is appropriate for testing this relationship, due to direct democracy and the federal structure of the country that encourage active citizen involvement in monitoring political processes (Frey and Stutzer 2000; Dorn et al. 2008). In addition, access to high-quality, longitudinal Swiss data on individual well-being and participation patterns brings a clear advantage to the present study in examining causality compared to previous research efforts in the domain.

By using Swiss Household Panel (SHP) data, this study elucidates the relationship between SWB and participation, and proposes to answer the following: how does SWB affect individual political engagement? And is this influence stronger than the impact of participation on SWB? Firstly, the study argues that from a conceptual 
point of view, it is likely that SWB precedes and affects the decision to participate, instead of only being an outcome of political activity. Secondly, it discusses how the influence of SWB is likely to vary across political activities, by having a spurring effect on formal political participation and having a dampening effect on protest intentions. Finally, the reciprocal effects between SWB and political engagement are empirically tested.

\section{Linking SWB and political participation}

\subsection{Measuring SWB}

How we feel about ourselves and our lives influences how we behave in the public sphere. This statement has paved the way for SWB to become a societal and a political issue (Carpenter 2012). SWB influences attitudes, motivations, and preferences (Diener 1984; Veenhoven 2008). Some of them are political, explaining why there is a rationale to expect that SWB impacts the willingness to participate in political processes.

While a state of feeling well is intuitively recognised by most of us, different approaches have been applied across disciplines in order to understand and define human well-being. In economics, SWB is compared to utility in explaining human behaviour and preferences (Dolan et al. 2008; Frey and Stutzer 2010), while sociologists consider SWB as an individual psychological state that explains social behaviour at the collective level (Diener et al. 1993), and positive psychology sees it as an indicator of optimal human functioning and thriving (Diener 2000, 2012; Oishi et al. 2007). Despite these different approaches, SWB has often been measured through self-reporting in surveys, due to the inherently personal nature of the construct. Likert scales of general life satisfaction or happiness are widely used across disciplines to measure SWB in national and comparative surveys.

Life satisfaction captures a global assessment of the quality of life, as opposed to any domain-specific evaluations, and it is based on comparisons that persons make against their own standard, instead of being externally imposed (Diener et al. 1985). Meanwhile, as informative as the life satisfaction scale is, SWB is increasingly recognised as being a multi-dimensional concept. General life satisfaction is a retrospective construct that measures only the evaluative dimension of SWB (Diener et al. 1985; Veenhoven 2008; Jeffrey et al. 2015).

A second, emotional dimension of well-being is composed of the positive and negative emotions that persons experience in daily life. Positive emotions can be experiences such as joy, energy, and enthusiasm, while negative emotions entail anger, anxiety, sadness, and related feelings. Emotional well-being is influenced by mood and is therefore less stable in time than other well-being dimensions (Diener 
2000; Diener et al. 2003). ${ }^{1}$ However, emotional well-being has also been described as a measure of the "emotional quality" (Kahneman and Deaton 2010) of everyday experiences, and their frequency and intensity.

Research has drawn different conclusions on the relationship between SWB and political participation depending on the SWB dimension under analysis (see e.g. Flavin and Keane 2011; Bühlmann 2016). It is therefore appropriate to differentiate between SWB dimensions when explaining the linkages between well-being and political activity (these differences are discussed in chapters 2.4-2.6). Likewise, it is necessary to consider how SWB relates to different types of political activity and, in the context of this study, the opportunities in Switzerland to exert political influence.

\subsection{Formal and protest-oriented political activity}

Despite that voting is still a cornerstone of citizen participation in politics in most established democracies, other political activities have been gaining importance in recent decades with the increasing aggregate levels of education and political sophistication of the citizenry (Inglehart 1997; Stolle and Hooghe 2011). Several typologies of political participation have been proposed over the years (Verba and Nie 1972; Barnes et al. 1979; Dalton 2006; Van Deth et al. 2007; Marien et al. 2010), distinguishing activities by the mechanism that triggers participation, the nature of the act, or the goal of the activity. Formal political activities ${ }^{2}$ aim to influence political decision-making from within the political system in place (Ekman and Amnå 2012). In addition to electoral participation and voting in popular votes or referenda, party membership, contacting a politician, or campaigning are considered formal participation. Protest participation, on the other hand, aims to influence decision-making from outside the established political system (Kaase 1999; Cornwall 2004; Hooghe and Marien 2013). Protest activities, such as strikes, boycotts, or demonstrations, use disruptive tactics to exert political influence.

\subsection{Political participation in Switzerland}

The Swiss political system is unique in its widespread use of direct democracy and the federal structure of the country that enables Swiss citizens to cast a ballot, in addition to elections, several times per year through popular votes. The Swiss are called on approximately four times a year to vote and are invited to vote on 15 federal

1 Research has also referred to eudemonic well-being, which relates to feelings of psychological empowerment (Zimmerman and Rappaport 1988; Bühlmann 2016), personal mastery, and a sense of being in control over one's life, as well as to social well-being, which entails, for example, being embedded in strong social networks and receiving emotional support when needed (Keyes 1998). These two other dimensions of well-being, as important as they are to a good life, will not be the focus of this research, mainly due to data availability in the SHP.

2 In addition to federal votes, citizens decide on a number of municipal and cantonal issues every year. 
proposals per year on average. ${ }^{3}$ Another unique feature of electoral participation in Switzerland is the significantly lower voter turnout than in most other Western democracies, both with regard to elections and popular votes. One possible explanation to the low intensity of voter participation is 'voter fatigue', as citizens are called on many times a year to vote on a full range of local, cantonal, and federal issues (Jackman and Miller 1995; Ladner 2002). On the other hand, small-scale democracy is thought to favour turnout, due to greater accessibility and understanding of the decision-making processes, stronger identification with the matters at hand, and the greater influence of social control (Dahl and Tufte 1973; Ladner 2002).

Protest participation in Switzerland is moderately common at the European level, yet protesting is, possibly with the exception of boycotting, less widespread than in neighbouring France, Italy, or Germany (Quaranta 2013). Compared to neighbouring countries, the lower eagerness to protest in Switzerland could be explained by direct democracy (Fatke and Freitag 2013), which give citizens ample opportunities to contest political decisions through formal channels of participation. Nevertheless, research has argued that a moderate resurgence of protest participation has taken place in the Swiss political landscape since the early 2000s (Hutter and Giugni 2009).

\subsection{Causality between SWB and political participation}

Earlier research has found positive associations between different dimensions of SWB and voting in elections (Weitz-Shapiro and Winters 2011; Bühlmann 2016; Liberini et al. 2017), working in parties and campaigning (Flavin and Keane 2011), and political activism (Klar and Kasser 2009). Despite the merits of these efforts to shed light on the linkages and synergies between SWB and political behaviour, research in the domain is still in its infancy. Specifically, past research remains inconclusive on whether political activity enhances well-being, whether well-being leads to participation, or whether a feedback effect is the most likely.

A major limitation in the literature is that most research in the domain relies on cross-sectional analysis. The few studies that explicitly test for causality between SWB and participation have found mixed evidence (e. g. Weitz-Shapiro and Winters 2008, 2011; Pirralha 2017). By using Dutch panel data, Pirralha (2017) discovered that SWB and participation were not significantly related, whereas Weitz-Shapiro and Winters $(2008,2011)$ tested the relationship in Latin American countries and showed that it is likely to go from SWB to participation. ${ }^{4}$ in Latin American countries and showed that it is likely to go from SWB to participation. ${ }^{5}$

3 In addition to federal votes, citizens decide on a number of municipal and cantonal issues every year.

4 The authors used quasi-experimental methods and sophisticated regression modelling, contrary to panel data.

5 It is worth mentioning the seminal work by Frey and Stutzer (2010), and the research by Dorn and his colleagues (2008), which uses longitudinal data to test the effect of institutions of direct 
While cross-sectional studies are in a less favourable position to infer causation, many of them argue that political participation would positively influence SWB on a conceptual level, mainly through the positive effects that participation has on the sentiment of individual competence, efficacy, and a sense of belonging and contributing to society (e. g. Klar and Kasser 2009; Pacheco and Lange 2010; Bühlmann 2016). These findings reflect a long-standing tradition in political theory that views the act of participating in the political process as valuable in creating procedural utility to the individual citizen and thereby having a positive effect on quality of life (Dreze and Sen 2002; Weitz-Shapiro and Winters 2008).

This dominant view has, however, been challenged (Oishi et al. 2007); especially in view of the scarce longitudinal evidence in support of the argument, it is not conceptually straightforward to assume that causality would run from political participation to SWB. Why would the sole act of participating in a political act, which most people only do by voting on occasion, have such general effects on SWB? And why would a political act lead to higher SWB when the objective of the activity is in many cases not fulfilled (Bühlmann 2016)?

In addition, considering the evidence of how poor (physical) health decreases political activity (Denny and Doyle 2007; Mattila et al. 2013; Pacheco and Fletcher 2015), one may draw parallels with the influence of SWB on political participation. Since the inverse relationship (i.e. that abstention from political activity would deteriorate health) hardly seems plausible, one may wonder if opting out of political activities would really decrease SWB. Claiming that political participation necessarily precedes SWB does not only leave these questions unanswered, but it also ignores the psychological processes that precede the choice to participate in political activities.

Due to these considerations, it is conceptually likely that SWB precedes political participation. It is arguable that the relationship is characterised by reciprocal effects; however, while participation can enhance SWB through sentiments of efficacy and belonging to society, it is likely that SWB affects whether or not persons participate in the first place. Therefore, it is expected that $S W B$ precedes and affects individual political engagement $\left(H_{p}\right)$. In chapters 2.5 and 2.6, this study will discuss in depth the influence of SWB on political activity.

\subsection{SWB as a resource for formal political participation}

SWB can be considered as a psychological resource for the purpose of political participation, due to its positive influence on self-efficacy and motivation to invest time and effort into political activities (Sahu and Rath 2003). Conversely, not feeling well in life has a tendency to lessen motivation and efficacy, and thereby depress participation (Ojeda 2015). The influence of SWB can be understood as being similar to

democracy on well-being in Switzerland, and finds that direct democracy enhances SWB among the Swiss. However, the focus of these studies has been on the linkages between SWB and the political context of the country, instead of actual participation by individuals. 
the effect of physical health on participation; even if low well-being does not create a physical obstacle to participate in the way poor physical health may (Denny and Doyle 2007; Mattila et al. 2013), not feeling well in life is psychologically burdensome and energy-consuming to deal with for the individual, and consequently affects the ability to engage in societal activities, such as political acts.

Considering the question from the perspective of Maslow's motivational theory (Maslow 1954), while the fulfilment of any aspect of human needs contributes to overall well-being, self-actualisation tends to only be achieved at moderate to high levels of well-being (Hagerty 1999; Koltko-Rivera 2006; Tay and Diener 2011). The act of pursuing higher societal and personal goals through political engagement can undoubtedly be considered as self-actualisation, and thus more likely to occur when individuals are feeling good about the other, more fundamental aspects of their lives (Inglehart and Welzel 2005; Veenhoven 2008).

Most current evidence of the relationship between SWB and political activity has argued for a positive influence on formal political participation specifically (e. g. Lyubomirsky et al., 2005; Flavin and Keane 2011). It is therefore expected in this study that SWB increases formal political participation (H2).

\subsection{Negative emotions increase political protest}

Meanwhile, SWB may not have the same favourable effect on political protest. In fact, it can be argued that SWB dampens political protest, since negative emotions tend to precede protest activities. Studies have found that negative emotional appraisals ${ }^{6}$ are more influential on protesting than cognitive comparisons that individuals draw against a standard (Van Zomeren et al. 2008), making the emotional dimension of SWB a better predictor of protesting than life satisfaction. In social psychology, emotions and appraisals have become increasingly popular explanations for why persons protest (Van Troost et al. 2013). They have been described as "accelerators" in the process of joining protest movements and as "amplifiers" of motivations to protest (Van Stekelenburg and Klandermans, 2013, 892), due to their influence on social perceptions and information-processing (Bodenhausen et al. 1994; Clark 2014). Persons protest to express frustration and injustice that they perceive (Lind and Tyler 1988; Dalton et al. 2010; Van Stekelenburg and Klandermans 2013). ${ }^{7}$ It is therefore expected that $S W B$ decreases protest intentions $\left(H_{3}\right)$.

$6 \quad$ The appraisal theory in psychology argues that emotions are extracted from our evaluations of situations and can cause different reactions between persons (Scherer et al. 2001).

7 Among negative emotions, anger is thought to have the strongest action potential (Van Stekelenburg et al. 2011; Van Troost et al. 2013). A specific question on anger was introduced to the SHP questionnaire in 2006 (wave 8), which restricts the analysis of the effect of anger on protesting to three waves only $(8-10)$. In this time span, the analysis showed no significant intra-individual effects. 


\section{Data and methods}

\subsection{The sample}

The three hypotheses stated above will be tested in SHP data. Conducted since 1999 , the SHP is an annual panel study based on a stratified random sample of private households and individuals living in Switzerland. All household members are interviewed mainly by telephone ${ }^{8}$ (Voorpostel et al. 2018). An advantage of testing the hypotheses in a single country instead of using cross-cultural data is that it helps to avoid common pitfalls related to country-specific political contexts (Hantrais 1999) and cultural differences in evaluating SWB (Diener 2000, 2012; Frey and Stutzer 2000).

The analytical sample includes nine waves (waves 2 to 10 , years 2000-2008) and consists of some 25100 person-years nested within 2790 respondents. The population and the timeframe are based on the availability of data on protest intentions. ${ }^{9}$ The population sample was drawn in 1999 (SHP I), and respondents who participated in 2000, and in any of the subsequent waves until 2008, are included in the analysis. Only adult Swiss citizens were considered for reasons of comparability between formal and protest participation.

\subsection{The measures}

SWB is measured through two dimensions: life satisfaction (evaluative SWB) and the frequency of positive and negative emotions (emotional SWB). Life satisfaction (In SHP: "In general, how satisfied are you with your life?") is a standard measure of SWB in surveys and has been found to have high internal consistency and temporal reliability (Diener et al. 1985).

The Positive and Negative Affect Schedule (PANAS) (Watson et al. 1988) measures emotional SWB. The PANAS comprises of two scales, one measuring positive emotions (In SHP: "Are you often plenty of strength, energy and optimism?") and the other negative emotions (In SHP: "Do you often have negative feelings, such as having the blues, being desperate, suffering from anxiety or depression?"). ${ }^{10}$ Both scales represent distinct aspects of emotional well-being, which is underlined by the moderate bivariate correlation ( $r=-0.49$ in the data). Moreover, the PANAS

8 Since 2010, face-to-face interviews and web-based surveys have been offered as alternatives for respondents who refuse or are reluctant to respond by telephone.

9 Since data on formal participation was collected until 2017 (except for years 2010, 2012-2013 and 2015-2016), the analysis was also conducted at a second stage on the entire available time span (2000-2017). The main results were robust (see results in Annex A2).

10 The PANAS questionnaire identifies over 50 mood terms relevant for either scale (Watson et al. 1988), and the SHP questions explicitly mention only a few of them. However, the SHP question formulation allows respondents to associate additional related emotions to their answers than those that are explicitly asked for. 
scales have been shown to be internally consistent and stable at intermediate time spans (Watson et al. 1988).

Formal and protest engagement are measured by the usual frequency of participation in federal popular votes (In SHP: "Let's suppose that there are 10 federal polls in a year. How many do you usually take part in?"), and by future intentions of boycotting, striking, and demonstrating (In SHP: "If 0 means 'never', and 10 'certainly' [...] to what extent, in the future, you are prepared to take part in a [boycott/strike/demonstration]?”).

Both the SWB and the political activity measures have slightly to moderately asymmetrical distributions. ${ }^{11}$ Robustness checks suggest, however, that the data structure is not problematic for the use of OLS techniques in the analytical models. ${ }^{12}$ The asymmetries are fairly common in survey data: negative emotions may be moderately underreported due to influences of social desirability (Kozma and Stones 1987; Diener 1994), and voting is widely considered to be sensitive to overreporting (e.g. Silver et al. 1986). In the SHP, 74\% of persons reported in at least one wave to participate in all popular votes, and less than $10 \%$ declared to never vote. These numbers deviate significantly from official turnout statistics, which averaged 44\% in the 2000-2008 period (FSO 2019). Protest intentions are less skewed than voting, yet $57 \%$ of persons declared at least once to never consider boycotting, $66 \%$ to never consider striking, and $56 \%$ to never consider demonstrating. At the other extreme, $39 \%$ of respondents reported at least once to certainly considering boycotting, compared to $26 \%$ for striking, and $30 \%$ for protesting. In this context, it is important to recall that panel attrition may particularly affect the analysis of political participation, since persons who stay in the panel tend to also be more politically active (Voorpostel et al. 2018).

\subsection{The method}

Fixed-effects OLS regressions are estimated in the data to encounter for withinindividual change in SWB and political activity, and to identify potential causal effects. The fixed-effects model is essentially a multilevel model where observations are nested within individuals, and where the fixed-effects coefficient expresses the variation over time in the individual-specific mean of a construct. An advantage of fixed-effects models is that they get rid of time-constant heterogeneity between individuals that may be correlated with the outcome, thereby making self-selection into treatment no longer an issue (Allison 2009). In this way, fixed-effects estimation provides a significant advantage over other methods in order to estimate the causal effect of a predictor on an outcome. When estimating individual change,

11 Skewness: life satisfaction: -1.01 ; negative emotions: 1.24 ; positive emotions: -0.99 ; voting: -1.48 ; boycotting: 0.16 ; striking: 0.49 ; demonstrating: 0.27 .

12 The models were tested by applying log transformation on the dependent variables and by z-standardising the predictors, which did not change the substantive conclusions of the results. 
one shall recall that the error terms are likely to correlate within individuals across time. Therefore, the standard errors reported in the models are panel-robust, i.e. clustered by respondents.

\subsection{The covariates}

The models control for the influence of sociodemographic confounders and political attitudes. It is widely acknowledged that objective resources, such as education and income, positively influence political engagement, and may also be related to SWB (Witter et al. 1984; Diener et al. 1993; Brady et al. 1995; Kahneman and Deaton 2010). Income is measured subjectively (i.e. satisfaction with the financial situation of the household), as it can be considered a better proxy of the quality of life than objective income measures (Ackerman and Paolucci 1983), in addition to being less sensitive to item non-response. It is worth noting that, since fixed-effects models only use within-individual variation to estimate effects, the influence of time-constant characteristics, such as gender or social origin ${ }^{13}$, cannot be estimated by these models; on the other hand, the models implicitly control for the influence of these time-constant traits (Allison 2009).

Among political attitudes, the models control for left-right self-identification, political trust, satisfaction with democracy, and self-perceptions of political influence. These attitudes are likely to influence whether individuals participate through formal channels of political activity, through protest acts, or whether they abstain from taking part altogether (Kaase 1999; Van Deth et al. 2007).

Finally, the models control for wave-effects, in order to account for the influence of the political context on political engagement in specific years. For instance, the overall political climate may encourage protesting in certain years, and also spur or dampen participation in popular votes, depending on the perceived importance of the topics voted on.

\section{Empirical results and discussion}

\subsection{Bivariate relationship}

Cross-sectional analysis of the data gives a first indication of the bivariate relationship between SWB and political engagement. Voting is positively correlated with life satisfaction $(\rho=0.11)$ and positive emotions $(\rho=0.06)$, while having a negative relationship with negative emotions $(\rho=-0.09)$. Among protest intentions, SWB is negatively correlated with boycotting ( $\rho=-0.09$ for life satisfaction, $\rho=-0.06$ for positive emotions, and $\rho=0.08$ for negative emotions), striking ( $\rho=-0.11$ for life

13 The models were also tested separately for robustness by gender, and by parents' social origin (by dual profession categories: unskilled vs. skilled). These analyses did not alter the substantive conclusions of the results. 
Table 1 Cross-sectional summary of variables, SHP 2000-2008

\begin{tabular}{llc}
\hline Variable & Mean & Std. Dev. \\
\hline Voting in federal popular votes & 8.03 & 2.81 \\
Future boycott intentions & 4.28 & 3.66 \\
Furure strike intentions & 3.50 & 3.53 \\
future demonstration intentions & 4.00 & 3.54 \\
Life satisfaction & 8.06 & 1.35 \\
Negative feelings & 1.92 & 1.97 \\
Positive feelings & 7.39 & 1.70 \\
Satisfaction with financial situation & 7.36 & 1.95 \\
Feeling of political influence & 3.96 & 2.52 \\
Left-right self-identification & 4.65 & 2.07 \\
Trust in the Federal Governement & 5.65 & 2.03 \\
Satisfaction with democracy & 6.13 & 1.79 \\
& & \\
Education, 3 levels & $\%$ & \\
low \\
mid-level \\
high \\
n(individuals): 2790
\end{tabular}

Note: Statistics for period-indicators (waves) are not shown. All variables are scales (0-10) except for education, which is a categorical indicator.

satisfaction, $\rho=-0.07$ for positive emotions, and $\rho=0.11$ for negative emotions), and demonstrating ( $\rho=-0.10$ for life satisfaction, $\rho=-0.06$ for positive emotions, and $\rho=0.12$ for negative emotions). While the correlations are moderate in magnitude, all associations are statistically significant at the $0.05-$ level and have the expected direction.

\subsection{Fixed-effects models}

A main purpose of this study is to shed light on the direction of the causality between well-being and political engagement. For that purpose, table 2 displays the standardised fixed-effects estimators (FE), their standard errors and significance for SWB and political activity retrieved from models that estimate the influence of SWB on political engagement, as well as the reverse causal relationship. The results can be compared by systematically reversing the dependent and independent variables between the models; in other words, by estimating the effect of SWB on political activity, and comparing the results to the effect of participation on SWB. By standardising the coefficients, the relative effects of SWB and political activity can be compared. To maximise comparability, all models include the same control variables; only the outcome and the main independent variables (either SWB or 
Table 2

Fixed-effects estimators of SWB and political engagement; two directions of causality

\begin{tabular}{ccccc}
\hline Predictor at T & & Outcome at T & FE (std.) & SE \\
\hline Life satisfaction & $\rightarrow$ & Voting & -.0056 & .0068 \\
Voting & $\rightarrow$ & Life satisfaction & -.0056 & .0136 \\
Negative emotions & $\rightarrow$ & Voting & -.0001 & .0066 \\
Voting & $\rightarrow$ & Negative emotions & -.0006 & .0134 \\
Positive emotions & $\rightarrow$ & Voting & .0043 & .0054 \\
Voting & $\rightarrow$ & Positive emotions & .0111 & .0138 \\
\hline Life satisfaction & $\rightarrow$ & Boycott intentions & -.0006 & .0075 \\
Boycott intentions & $\rightarrow$ & Life satisfaction & .0049 & .0103 \\
Negative emotions & $\rightarrow$ & Boycott intentions & .0106 & .0077 \\
Boycott intentions & $\rightarrow$ & Negative emotions & -.0083 & .0104 \\
Positive emotions & $\rightarrow$ & Boycott intentions & .0095 & .0067 \\
Boycott intentions & $\rightarrow$ & Positive emotions & .0199 & .0119 \\
\hline Life satisfaction & $\rightarrow$ & Strike intentions & -.0065 & .0073 \\
Strike intentions & $\rightarrow$ & Life satis faction & -.0191 & .0116 \\
Negative emotions & $\rightarrow$ & Strike intent ions & $.0186^{*}$ & .0073 \\
Strike intentions & $\rightarrow$ & Negative emotions & .0219 & .0113 \\
Positive emotions & $\rightarrow$ & Strike intentions & -.0033 & .0061 \\
Strike intentions & $\rightarrow$ & Positive emotions & $-.0301^{*}$ & .0129 \\
\hline Life satisfaction & $\rightarrow$ & Demonstration intentions & .0011 & .0072 \\
Demonstration intentions & $\rightarrow$ & Life satis faction & .0013 & .0117 \\
Negative emotions & $\rightarrow$ & Demonstration intentions & $.0234^{* * *}$ & .0070 \\
Demonstration intentions & $\rightarrow$ & Negative emotions & $.0252^{*}$ & .0115 \\
Positive emotions & $\rightarrow$ & Demonstration intentions & .0069 & .0058 \\
Demonstration intentions & $\rightarrow$ & Positive emotions & .0084 & .0124 \\
\hline
\end{tabular}

Note: $\mathrm{FE}=$ standardised fixed-effects estimators. Standard errors $(\mathrm{SE})$ are panel robust. Significance levels: ${ }^{*} p<0.05 ;{ }^{* *} p<0.01 ;{ }^{* *} p<0.001$.

activity/intention) are exchanged between the models. The full results of the models are displayed in Annex A1.

\subsection{SWB and formal political participation}

Contrary to expectations, the results in Table 2 suggest that SWB does not significantly affect individual voting habits, irrespective of the SWB dimension under consideration. Meanwhile, the results show no evidence that voting would increase SWB, contrary to what has been assumed in previous work on the link between participation and well-being (e. g. Frey and Stutzer 2000; Dolan et al. 2008; Pacheco and Lange 2010). This is noteworthy, as it challenges the dominant view in literature that claims that political participation would produce utility for the individual and 
thereby favour SWB. The analysis suggests that SWB and voting are only weakly related, thereby reflecting the conclusions of previous studies (Weitz-Shapiro and Winters 2011; Pirralha 2017). By consequence, the expectations laid out in H2 and $\mathrm{H} 1$ cannot be confirmed with regards to formal political participation.

A possible explanation to this unexpected result relates to the limited change in individual voting habits, and the preponderance of differences between individuals in the panel. The differences in voting between individuals are considerable, explaining up to $79 \%$ of the variance in the model ( rho $=0.79)$, yet this variation does not contribute to identifying the causal effect of SWB on voting. Furthermore, a descriptive analysis of the sample preliminarily indicates that individual voting habits stay relatively stable in the panel: among the $74 \%$ who ever reported participating in all popular votes, nearly $70 \%$ do not change their response over time. It indicates that persons in the panel who vote regularly will continue to do so, irrespective of changes in their SWB, thus reflecting the conclusions of earlier research on the strong habit-forming effect of previous voter participation (Gerber et al. 2003; Cutts et al. 2009).

\subsection{SWB and protest intentions}

The results align better with the expectations of $\mathrm{H}_{3}$, showing that negative emotions significantly increase protest intentions. The magnitude of the effect is moderate but statistically significant for two of the three protest forms: a unit increase in negative feelings increases individuals' strike intentions by 3 percentage points on average $(B=0.033 ; \beta=0.019 ; p<0.05)$, and their readiness to demonstrate by 4 percentage points $(B=0.042 ; \beta=0.023 ; p<0.001)$. By contrast, the effect of SWB on boycott intentions does not reach statistical significance, which is an interesting contrast to the two other protest forms. The difference may be related to the distinct nature of boycotting compared to striking and demonstrating, as boycotting also entails political consumerism that is strongly related to lifestyle politics, and less related to direct contentious action (Stolle et al. 2005). However, further analysis, beyond the scope of this study, is needed to confirm this assumption.

Meanwhile, the results also show a reverse effect. Demonstration intentions increase negative emotions by 1.4 percentage points $(B=0.014 ; \beta=0.025$, $\mathrm{p}<0.05)$, and strike intentions decrease positive emotions by 1.5 percentage points $(B=-0.015 ; \beta=-0.030, p<0.05)$. The difference in the magnitude of the effect of demonstration intentions on negative emotions $(\beta=0.025)$ compared to the reverse effect $(\beta=0.023)$ is small, yet the significance test show stronger evidence in favour of emotions preceding intentions than the other way around. In addition, there is no evidence of a significant effect of striking intentions on negative emotions, by contrast to the reverse effect $(B=0.019 ; \beta=0.007, p<0.05)$.

The depressing effect of strike intentions on positive emotions is, however, remarkable, especially since the reverse effect is not significant and also considerably 
smaller in magnitude ( $\beta=-0.030$ vs. $\beta=-0.003$ ). While suggesting that strike intentions indeed precede SWB, the association between positive emotions and protest intentions remains negative, irrespective of the causal direction under consideration. These results align with studies arguing that participation in political protest would be negatively correlated with well-being (Klar and Kasser 2009), and echo previous research on the importance of emotions in explaining protesting (Bodenhausen et al. 1994; Van Stekelenburg and Klandermans 2013; Van Troost et al. 2013), while also resulting from protest (Jasper 1998).

\subsection{Assessing causality}

The results of the analysis indicate that the nature of the underlying causal mechanism between well-being and political protest is most likely reciprocal: negative emotions increase protest intentions, and these intentions, to a certain extent, decrease well-being. This conclusion reflects a conceptualisation of the link as a "feedback"mechanism for which some scholars have argued (Oishi et al. 2007; Weitz-Shapiro and Winters 2011). In broad terms, the analysis shows stronger evidence of SWB decreasing demonstration intentions than the other way around. However, the evidence is mixed for strike intentions, as these do not only seem to result from negative emotions, but they also result in fewer positive emotions. For these reasons, the evidence in favour of SWB as a predictor of protest intentions is not conclusive enough to reject the null hypothesis $\left(\mathrm{H}_{1}\right)$.

A limitation of the chosen approach is that it does not account for the stability of the constructs across time. The cross-lagged panel design has become popular for the estimation of autoregressive and reciprocal effects (Selig and Little 2012). However, cross-lagged panel models do not separate between inter- and intra-individual change; while the parameter estimates are affected by changes within individuals, they are not specific to relationships within persons (Selig and Little 2012). In other words, one cannot separate between effects that stem from differences between and within individuals. This is a major drawback for the aims of this research, given that differences between individuals explain the majority of the variance (between $66 \%$ for boycott and $79 \%$ for voting), and confounding between inter- and intra-person variance would seriously compromise the ability to identify individual-level causal effects. The cross-lagged panel model is therefore less appropriate for the present study.

\section{Conclusions}

\subsection{SWB decreases protest, and protest decreases SWB}

This research contributes to the literature on the psychological explanations of political activity by examining the effect of SWB on formal and protest-oriented political engagement within individuals over time. The results show that SWB 
decreases protest intentions, thus reflecting earlier research that consider negative emotions to be important predictors of protesting (Bodenhausen et al. 1994; Van Troost et al. 2013). A causality test further indicates that the relationship between SWB and protest intentions is likely reciprocal. Despite the analysis suggesting that the effect of SWB on protest intentions is stronger than the reverse effect, further empirical testing would be welcome before confirming this assumption. Meanwhile, the results show no effect of SWB on formal participation, contrary to the expectations, thereby aligning with previous panel studies on the relationship (e.g. Pirralha 2017). In the absence of any significant reverse effects, the findings of this study challenge previous research that consider political engagement to favour the development of SWB (e. g. Frey and Stutzer 2000; Dorn et al. 2008; Pacheco and Lange 2010), and indicate that future studies should carefully evaluate the expected causal relationship between well-being and political activity.

\subsection{A well-being gap in political decision-making?}

We have witnessed in the last decades a growing scholarly attention to SWB and its influence on citizen's engagement in politics. The importance of the topic is underlined by the potential political consequences of SWB; if SWB is recognised as a predictor of political participation, it could in principle decrease participation among citizens with low SWB and potentially engender a well-being gap in democratic decision-making.

Due to the absence of any significant relationship between SWB and formal participation, this research relativises the risk of a political well-being gap in Swiss society. Meanwhile, considering that SWB does affect individual readiness to engage in contentious political acts, one may ask to what extent increasing malaise among the population could result in actual contentious behaviour. Under which conditions do these latent forms of protesting turn into actual political protest? And can the occurrence of protest waves in Swiss society be traced back to changes in individual's SWB? Future research in this regard would be welcome in order to better understand the extent to which SWB contributes to protest events in Switzerland.

Finally, the recognition that SWB is linked to political protest has consequences on how policy-makers perceive the role of well-being in society, taking it out from the private sphere and also making well-being a political affair. By consequence, attention should be paid to citizen's SWB in anticipating and understanding protest that may turn from latent intentions to manifest behaviour in society. Meanwhile, paying attention to a citizen's well-being does not seem to be a fix for low turnout in a time when the legitimacy of the democratic institutions is increasingly contested in most established democracies, including Switzerland. The linkages between SWB and political engagement remain relevant both for scholarly purposes and from a policy-making point of view. 


\section{References}

Ackerman, Norleen and Beatrice Paolucci. 1983. Objective and Subjective Income Adequacy: Their Relationship to Perceived Life Quality Measures. Social Indicators Research 12(1): 25-48.

Allison, Paul D. 2009. Fixed Effects Regression Models. Vol. 160. Thousand Oaks, CA: SAGE publications.

Barnes, Samuel H., Klaus R. Allerbeck, Barbara G. Farah, Felix J. Heunks, Ronald F. Inglehart, M. Kent Jennings, Hans Dieter Klingemann, Alan Marsh, and Leopold Rosenmayr. 1979. Political Action: Mass Participation in Five Western Democracies. Beverly Hills, CA: SAGE Publications.

Bodenhausen, Galen V., Lori A. Sheppard, and Geoffrey P. Kramer. 1994. Negative Affect and Social Judgment: The Differential Impact of Anger and Sadness. European Journal of Social Psychology 24(1): 45-62.

Brady, Henry E., Sidney Verba, and Kay Lehman Schlozman. 1995. Beyond Ses: A Resource Model of Political Participation. The American Political Science Review 89(2): 271-94.

Bühlmann, Marc. 2016. Does Political Participation Make People Happy? Pp. 210-28 in Swiss Social Report 2016: Wellbeing, edited by Franziska Ehrler, Felix Bühlmann, Peter Farago, François Höpflinger, Dominique Joye, Pasqualina Perrig-Chiello, and Christian Suter. Zürich: Seismo-Verlag.

Carpenter, Daniel. 2012. Is Health Politics Different? Annual Review of Political Science 15: 287-311.

Clark, Margaret Sydnor. 2014. A Role for Arousal in the Link between Feeling States, Judgments, and Behavior. Pp. 265-289 in Affect and Cognition: 17 th Annual Carnegie Mellon Symposium on Cognition, edited by Margaret Sydnor Clark and Susan T. Fiske. New York, NY: Psychology Press.

Cornwall, Andrea. 2004. Introduction: New Democratic Spaces? The Politics and Dynamics of Institutionalised Participation. IDS Bulletin 35(2): 1-10.

Cutts, David, Edward Fieldhouse, and Peter John. 2009. Is Voting Habit Forming? The Longitudinal Impact of a GOTV Campaign in the UK. Journal of Elections, Public Opinion and Parties 19(3): 251-63.

Dahl, Robert Alan and Edward R. Tufte. 1973. Size and Democracy. Vol. 2. Stanford, CA: Stanford University Press.

Dalton, Russell. 2006. Citizen Politics. Public Opinion and Political Parties in Advanced Industrialized Democracies. Washington DC: CQ Press.

Dalton, Russell, Alix Van Sickle, and Steven Weldon. 2010. The Individual-Institutional Nexus of Protest Behaviour. British Journal of Political Science 40(1): 51-73.

Denny, Kevin J. and Orla M. Doyle. 2007. “... Take up Thy Bed, and Vote” Measuring the Relationship between Voting Behaviour and Indicators of Health. European Journal of Public Health 17(4): $400-401$.

Diener, Ed. 1984. Subjective Well-Being. Psychological Bulletin 95(3): 542-575.

Diener, Ed. 1994. Assessing Subjective Well-Being: Progress and Opportunities. Social Indicators Research 31(2): 103-157.

Diener, Ed. 2000. Subjective Well-Being: The Science of Happiness and a Proposal for a National Index. American Psychologist 55(1): 34-43.

Diener, Ed. 2012. New Findings and Future Directions for Subjective Well-Being Research. American Psychologist 67(8): 590-597.

Diener, Ed, Robert A. Emmons, Randy J. Larsen, and Sharon Griffin. 1985. The Satisfaction with Life Scale. Journal of Personality Assessment 49(1): 71-75.

Diener, Ed, Shigehiro Oishi, and Richard E. Lucas. 2003. Personality, Culture, and Subjective WellBeing: Emotional and Cognitive Evaluations of Life. Annual Review of Psychology 54(1): 403-425.

Diener, Ed, Ed Sandvik, Larry Seidlitz, and Marissa Diener. 1993. The Relationship between Income and Subjective Well-Being: Relative or Absolute? Social Indicators Research 28(3): 195-223. 
Dolan, Paul, Tessa Peasgood, and Mathew White. 2008. Do We Really Know What Makes Us Happy? A Review of the Economic Literature on the Factors Associated with Subjective Well-Being. Journal of Economic Psychology 29(1): 94-122.

Dorn, David, Justina AV Fischer, Gebhard Kirchgässner, and Alfonso Sousa-Poza. 2008. Direct Democracy and Life Satisfaction Revisited: New Evidence for Switzerland. Journal of Happiness Studies 9(2): 227-255.

Dreze, Jean and Amartya Sen. 2002. India: Development and Participation. New York, NY: Oxford University Press, USA.

Ekman, Joakim and Erik Amnå. 2012. Political Participation and Civic Engagement: Towards a New Typology. Human Affairs 22(3): 283-300.

Fatke, Matthias and Markus Freitag. 2013. Direct Democracy: Protest Catalyst or Protest Alternative? Political Behavior 35(2): 237-260.

FSO (Federal Statistical Office). 2019. Evolution de La Participation Aux Votations Populaires Fédérales. Statistics of elections and votes. Neuchâtel: Federal Statistical Office.

Flavin, Patrick and Michael J. Keane. 2011. Life Satisfaction and Political Participation: Evidence from the United States. Journal of Happiness Studies 13(1): 63-78.

Frey, Bruno S. and Alois Stutzer. 2000. Happiness, Economy and Institutions. The Economic Journal 110(466): 918-938.

Frey, Bruno S. and Alois Stutzer. 2010. Happiness and Economics: How the Economy and Institutions Affect Human Well-Being. Princeton, NJ: Princeton University Press.

Gerber, Alan S., Donald P. Green, and Ron Shachar. 2003. Voting May Be Habit-forming: Evidence from a Randomized Field Experiment. American Journal of Political Science 47(3): 540-550.

Hagerty, Michael R. 1999. Testing Maslow's Hierarchy of Needs: National Quality-of-Life across Time. Social Indicators Research 46(3): 249-271.

Hantrais, Linda. 1999. Contextualization in Cross-National Comparative Research. International Journal of Social Research Methodology 2(2): 93-108.

Hobfoll, Stevan E. 2002. Social and Psychological Resources and Adaptation. Review of General Psychology 6(4): 307-324.

Hooghe, Marc and Sofie Marien. 2013. A Comparative Analysis of the Relation between Political Trust and Forms of Political Participation in Europe. European Societies 15(1): 131-152.

Hutter, Swen and Marco Giugni. 2009. Protest Politics in a Changing Political Context: Switzerland, 1975-2005. Swiss Political Science Review 15(3): 427-461.

Inglehart, Ronald. 1997. Modernization and Postmodernization. Cultural, Economic, and Political Change in 43 Societies. Princeton, NJ: Princeton University Press.

Inglehart, Ronald and Christian Welzel. 2005. Modernization, Cultural Change, and Democracy: The Human Development Sequence. Cambridge MA: Cambridge University Press.

Jackman, Robert W. and Ross A. Miller. 1995. Voter Turnout in the Industrial Democracies during the 1980s. Comparative Political Studies 27(4): 467-492.

Jasper, James M. 1998. The Emotions of Protest: Affective and Reactive Emotions in and around Social Movements. Sociological Forum 13(3): 397-424.

Jeffrey, Karen, Saamah Abdallah, and Annie Quick. 2015. Europeans' Personal and Social Wellbeing Topline Results from Round 6 of the European Social Survey. London: European Social Survey ERIC.

Kaase, Max. 1999. Interpersonal Trust, Political Trust and Non-institutionalised Political Participation in Western Europe. West European Politics 22(3): 1-21.

Kahneman, Daniel and Angus Deaton. 2010. High Income Improves Evaluation of Life but Not Emotional Well-Being. Proceedings of the National Academy of Sciences 107(38): 16489-16493.

Keyes, Corey Lee M. 1998. Social Well-Being. Social Psychology Quarterly 61(2): 121-140. 
Klar, Malte and Tim Kasser. 2009. Some Benefits of Being an Activist: Measuring Activism and Its Role in Psychological Well-Being. Political Psychology 30(5): 755-777.

Koltko-Rivera, Mark E. 2006. Rediscovering the Later Version of Maslow's Hierarchy of Needs: Self-Transcendence and Opportunities for Theory, Research, and Unification. Review of General Psychology 10(4): 302-317.

Kozma, Albert and Michael J. Stones. 1987. Social Desirability in Measures of Subjective Well-Being: A Systematic Evaluation. Journal of Gerontology 42(1): 56-59.

Ladner, Andreas. 2002. Size and Direct Democracy at the Local Level: The Case of Switzerland. Environment and Planning C: Government and Policy 20(6): 813-828.

Liberini, Federica, Michela Redoano, and Eugenio Proto. 2017. Happy Voters. Journal of Public Economics 146: 41-57.

Lind, E. Allan and Tom R. Tyler. 1988. The Social Psychology of Procedural Justice. New York, NY: Springer Science \& Business Media.

Lyubomirsky, Sonja, Laura King, and Ed Diener. 2005. The Benefits of Frequent Positive Affect: Does Happiness Lead to Success? Psychological Bulletin 131(6): 803-55.

Marien, Sofie, Marc Hooghe, and Ellen Quintelier. 2010. Inequalities in Non-Institutionalised Forms of Political Participation: A Multi-Level Analysis of 25 Countries. Political Studies 58(1): 187-213.

Maslow, Abraham. 1954. Motivation and Personality. New York, NY: Harper and Brothers.

Mattila, Mikko, Peter Söderlund, Hanna Wass, and Lauri Rapeli. 2013. Healthy Voting: The Effect of Self-Reported Health on Turnout in 30 Countries. Electoral Studies 32(4): 886-891.

Oishi, Shigehiro, Ed Diener, and Richard E. Lucas. 2007. The Optimum Level of Well-Being: Can People Be Too Happy? Perspectives on Psychological Science 2(4): 346-360.

Ojeda Christopher. 2015. Depression and Political Participation. Social Science Quarterly 96(5):1226-1243.

Pacheco, Gail and Thomas Lange. 2010. Political Participation and Life Satisfaction: A Cross-European Analysis. International Journal of Social Economics 37(9): 686-702.

Pacheco, Julianna and Jason Fletcher. 2015. Incorporating Health into Studies of Political Behavior: Evidence for Turnout and Partisanship. Political Research Quarterly 68(1): 104-116.

Pirralha, André. 2017. Political Participation and Wellbeing in the Netherlands: Exploring the Causal Links. Applied Research in Quality of Life 12(2): 327-341.

Quaranta, Mario. 2013. Measuring Political Protest in Western Europe: Assessing Cross-National Equivalence. European Political Science Review 5(3): 457-482.

Radcliff, Benjamin. 2001. Politics, Markets, and Life Satisfaction: The Political Economy of Human Happiness. American Political Science Review 95(4): 939-952.

Rosenstone, Steven J., John Mark Hansen, and Keith Reeves. 1993. Mobilization, Participation, and Democracy in America. New York, NY: Palgrave Macmillan.

Sahu, Fakir Mohan and Sangeeta Rath. 2003. Self-Efficacy and Wellbeing in Working and Non-Working Women: The Moderating Role of Involvement. Psychology and Developing Societies 15(2): 187-200.

Samman, Emma. 2007. Psychological and Subjective Well-Being: A Proposal for Internationally Comparable Indicators. Oxford Development Studies 35(4): 459-486.

Scherer, Klaus R., Angela Schorr, and Tom Johnstone. 2001. Appraisal Processes in Emotion: Theory, Methods, Research, edited by Klaus R. Scherer, Angela Schorr and Tom Johnstone. New York, NY: Oxford University Press.

Selig, James P. and Todd D. Little. 2012. Autoregressive and Cross-Lagged Panel Analysis for Longitudinal Data. Pp. 265-278 in Handbook of Developmental Research Methods, edited by Brett Laursen, Todd D. Little and Noel A. Card. New York, NY: Guilford Press.

Silver, Brian D., Barbara A. Anderson, and Paul R. Abramson. 1986. Who Overreports Voting? American Political Science Review 80(2): 613-624. 
Stolle, Dietlind and Marc Hooghe. 2011. Shifting Inequalities: Patterns of Exclusion and Inclusion in Emerging Forms of Political Participation. European Societies 13(1): 119-142.

Stolle, Dietlind, Marc Hooghe, and Michele Micheletti. 2005. Politics in the Supermarket: Political Consumerism as a Form of Political Participation. International Political Science Review 26(3): 245-269.

Tay, Louis and Ed Diener. 2011. Needs and Subjective Well-Being around the World. Journal of Personality and Social Psychology 101(2): 354-365.

Taylor, Shelley E., Margaret E. Kemeny, Geoffrey M. Reed, Julienne E. Bower, and Tara L. Gruenewald. 2000. Psychological Resources, Positive Illusions, and Health. American Psychologist 55(1): 99-109.

Van Deth, Jan W., José Ramón Montero, and Anders Westholm. 2007. Citizenship and Involvement in European Democracies: A Comparative Analysis. Vol. 17. London: Routledge.

Van Stekelenburg, Jacquelien and Bert Klandermans. 2013. The Social Psychology of Protest. Current Sociology 61(5-6): 886-905.

Van Stekelenburg, Jacquelien, Bert Klandermans, and Wilco W. Van Dijk. 2011. Combining Motivations and Emotion: The Motivational Dynamics of Protest Participation. Revista de Psicologia Social 26(1): 91-104.

Van Troost, Dunya, Jacquelien Van Stekelenburg, and Bert Klandermans. 2013. Emotions of Protest. Pp. 186-203 in Emotions in politics: The Affect Dimension in Political Tension, edited by Nicolas Demertzis. London: Palgrave MacMillan.

Van Zomeren, Martijn, Tom Postmes, and Russell Spears. 2008. Toward an Integrative Social Identity Model of Collective Action: A Quantitative Research Synthesis of Three Socio-Psychological Perspectives. Psychological Bulletin 134(4): 504-535.

Veenhoven, Ruut. 2008. Sociological Theories of Subjective Well-Being. Pp. 44-61 in The Science of Subjective Well-being, edited by Randy J. Larsen and Michael Eid. New York: The Guilford Press.

Verba, Sidney and Norman H. Nie. 1972. Participation in America: Social Equality and Political Democracy. New York: Harper\& Row.

Verba, Sidney, Norman H. Nie, and Jae-on Kim. 1987. Participation and Political Equality: A SevenNation Comparison. Chicago, IL: University of Chicago Press.

Voorpostel, Marieke, Robin Tillmann, Florence Lebert, Ursina Kuhn, Oliver Lipps, Valérie-Anne Ryser, Erika Antal, Gian-Andrea Monsch, Nora Dasoki, and Boris Wernli. 2018. Swiss Household Panel User Guide (1999-2017), Wave 19, December 2018. Lausanne: FORS.

Watson, David, Lee Anna Clark, and Auke Tellegen. 1988. Development and Validation of Brief Measures of Positive and Negative Affect: The PANAS Scales. Journal of Personality and Social Psychology 54(6): 1063-1070.

Weitz-Shapiro, Rebecca and Matthew S. Winters. 2008. Political Participation and Quality of Life. Working Paper 638. Inter-American Development Bank, https://www.econstor.eu/ bitstream/10419/51523/1/585732140.pdf (21.11.2019).

Weitz-Shapiro Rebecca and Winters Matthew S. 2011. The Link Between Voting and Life Satisfaction in Latin America. Latin American Politics and Society 53(4): 101-126.

Witter, Robert A., Morris A. Okun, William A. Stock, and Marilyn J. Haring. 1984. Education and Subjective Well-Being: A Meta-Analysis. Educational Evaluation and Policy Analysis 6(2): 165-173.

Zimmerman, Marc A. and Julian Rappaport. 1988. Citizen Participation, Perceived Control, and Psychological Empowerment. American Journal of Community Psychology 16(5): 725-750. 


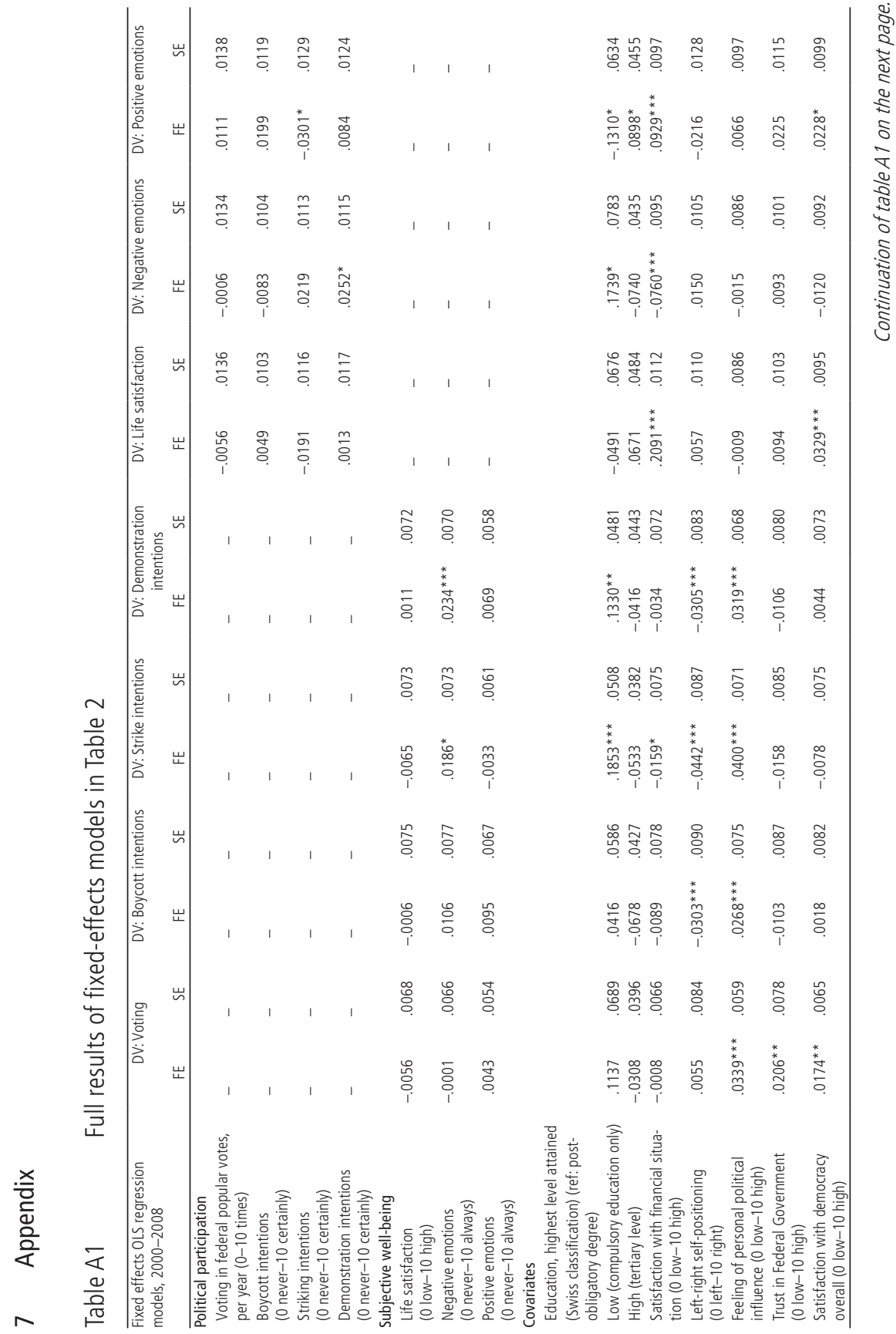




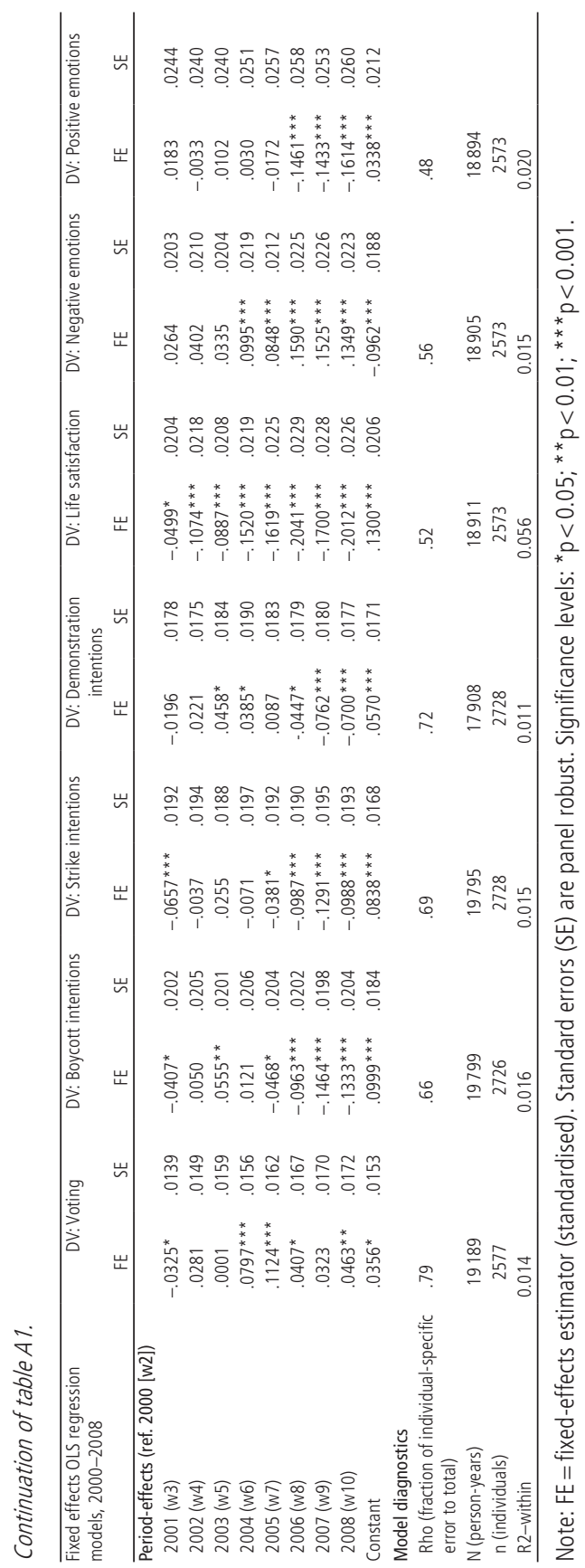




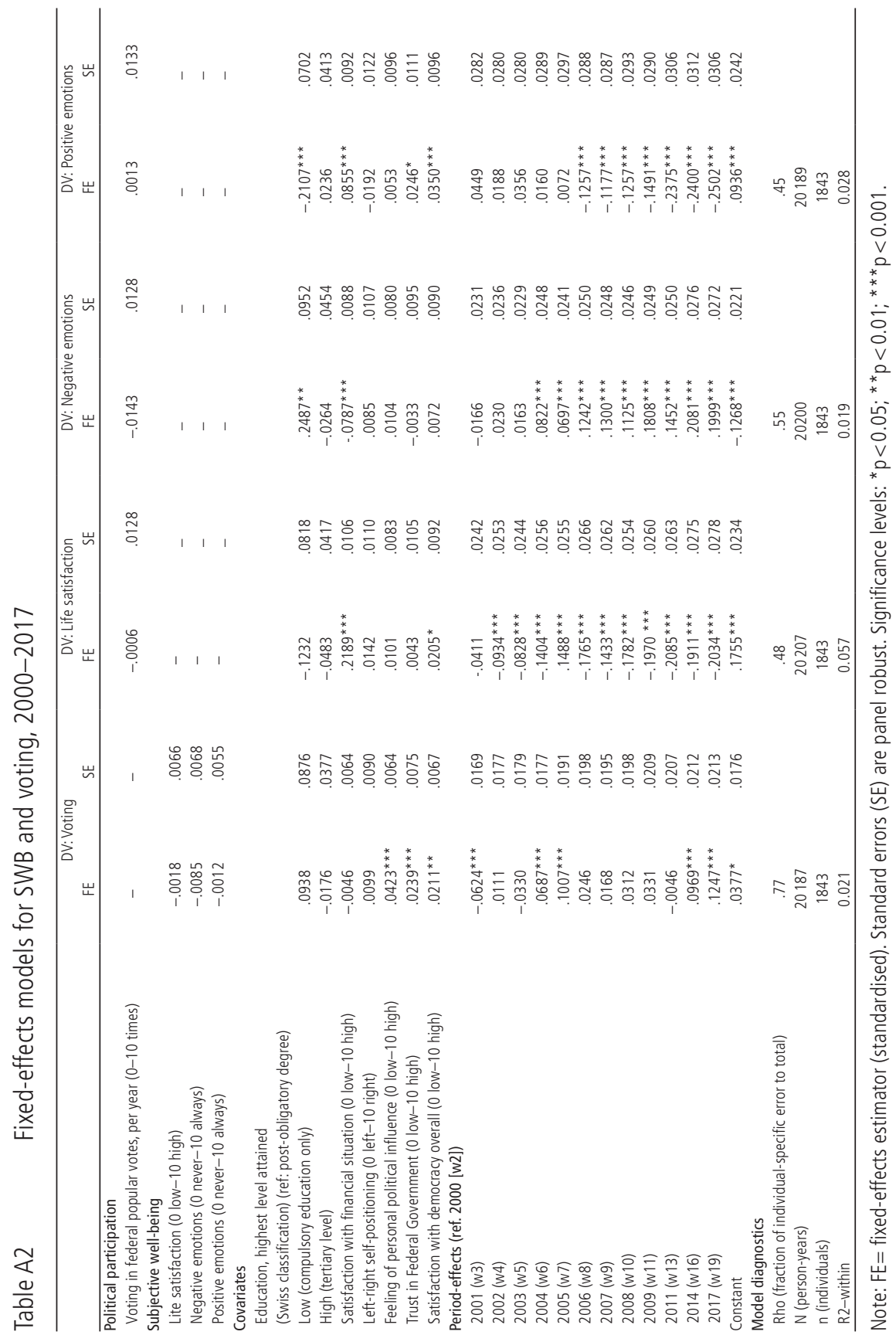

